\title{
Evaluation of Patient setup Accuracy and Determination of Optimal Setup Margin for External Beam Radiation therapy using Electronic Portal Imaging Device
} \author{
Tavakol ${ }^{2}$, Parvaneh Kiani ${ }^{2}$, Zeynab Fazli ${ }^{2}$ and Hamed Ghaffari ${ }^{5 *}$ \\ ${ }^{1}$ Department of Radiation Oncology, Aja University of Medical Sciences, Iran \\ ${ }^{2}$ Department of Radiation Oncology, Roshana Radiation Oncology Center, Iran \\ ${ }^{3}$ Department of Radiation Oncology, Iran University of Medical Sciences, Iran \\ ${ }^{4}$ Department of Radiation Oncology, Isfahan University of Medical Sciences, Iran \\ ${ }^{5}$ Department of Medical Physics, Iran University of Medical Sciences, Iran
}

SeyedHadi Molana ${ }^{1}$, Farshid Arbabi ${ }^{2}$, Mastaneh Sanei ${ }^{3}$, Elham Hashemi ${ }^{2}$, Mina Tajvidi $^{4}$, Aram Rostami $^{5}$, Asieh

Submission: May 23, 2018; Published: June 27, 2018

"Correspondence Address: Hamed ghaffari, Department of Medical Physics, School of Medicine, Iran University of Medical Sciences, Junction of Shahid Hemmat and Chamran Expressway, Tehran, Iran, Tel: +989118555899; Email: hamedghaffari1371@gmail.com

\begin{abstract}
Introduction: The setup errors in patient positioning during radiotherapyhave a critical role in the tumor control and overdose of normal tissues. The purpose of this study was to evaluate the patient setup errors and propose optimum planning target volume (PTV) for various treatment sites using electronic portal imaging device (EPID).

Methods: A total of 748 fractions were analyzed from 73 patients treated with 3DCRT for head and neck (H\&N), brain, pelvic and prostate. Population systematic and random errors and 3D vector of shifts were calculated. PTV margins for different confidence levels were determined using van Herk's formula.

Results: Population systematic and random errors were $0.7,0.86$ and $0.6 \mathrm{~mm}$ and $0.5,0.45$ and $0.9 \mathrm{~mm}$ for $\mathrm{H} \& \mathrm{~N}$ cases, $0.61,0.8$ and 0.93 $\mathrm{mm}$ and $0.3,0.4$ and $0.72 \mathrm{~mm}$ for brain cases, $1.3,1.26$ and $1.51 \mathrm{~mm}$ and $0.63,0.92$ and $0.94 \mathrm{~mm}$ for pelvic cases and $0.69,0.86$ and $1.0 \mathrm{~mm}$ and $2.11,2.3$ and $2.31 \mathrm{~mm}$ for prostate cases in vertical, longitudinal and lateral directions, respectively. Three-dimensional vector displacements $\geq 7$ $\mathrm{mm}$ was $0 \%$ for brain cases and rare for other treatment sites. PTV ${ }_{(90,95)}$ margins were less than $3 \mathrm{~mm}$ for $\mathrm{H} \& \mathrm{~N}$ and brain sites and are less than
\end{abstract} $5 \mathrm{~mm}$ for pelvic and prostate cases in three translational directions.

Conclusion: The setup errors depend on the tumor site. The use of image guidance technique is an effective tool for setup verification. Keywords: PTV margin;Systematic error;Random error; EPID; Patient setup uncertainty

\section{Introduction}

The aim of radiation therapy (RT) is to reliably maximize the dose to the target while minimizing the toxicity to the normal tissues. Therefore, daily treatment setup is considered as a critical requirement in RT for an accurate dose delivery. The planning target volume (PTV) is defined as the clinical target volume (CTV) plus a margin to account for patient positioning uncertainties, beam alignment and organ motion (i.e. setup margin and internal margin). Setup margins have a direct effect on the coverage of target volume. Thus, these should be optimized to prevent inadvertent irradiation of organ at risks (OARs) [1,2].
Setup uncertainties can be divided into two categories: systematic errors and random errors. Whereas the random errors blur the dose distribution, the systematic component of errors leads to a shift of the cumulative dose distribution relative to the target. The systematic errors are reproducible consistent errors, occurring in the same direction and magnitude but random (day-to-day) errors can vary in direction, magnitude and are unpredictable. The systematic errors in contrast to the random errors are more dangerous because they affect all treatment sessions. Thus, systematic errors may lead to the recurrence of the tumor or serious damage in normal organs [3]. 
The introduction of image guided RT (IGRT) allows to reduce the size of PTV-CTV expansion. Recently, image guidance techniques such as ExacTrac, cone beam computed tomography (CBCT) and electronic portal imaging devices (EPIDs) provide the accuracy of patient positioning and target localization for RT [4-6]. The widespread availability of EPIDs has led to it be an effective tool to decrease setup errors. Pre-treatment electronic portal images (EPIs) provide the evaluation of setup errors $[7,8]$. In this study, setup errors evaluation is doing using a portal image and a digitally reconstructed radiograph (DRR). The objective of this study was to quantify the inter-fractional setup errors and 3D vector lengths and calculate CTV-PTV margin for different treatment sites such as head and neck (H\&N), brain, pelvic and prostate by electronic portal images guidance and determine the optimal PTV margins.

\section{Methods and materials}

\section{Patient Selection}

Seventy-three patients with cancer treated with 3DCRT for sites such as head and neck (H\&N), brain, prostate and pelvic at Roshana Radiation Oncology Center, Iran between July 2017 and January 2018 were considered in this retrospective study. The distribution of patients was 11 patients with H\&N tumor, 15 patients with brain tumor, 30 pelvic cancer patients and 17 prostate cancer patients.

\section{Treatment Simulation and Planning}

At our institution, brain and H\&N patients were immobilized using the 3-point head only (brain patients) and 5-point headneck-shoulder (H\&N patients) thermoplastic mask with a headrest in the treatment position. One week prior to CT planning, the prostate cancer patients implanted 3 fiducial gold markers. The prostate patients had to empty rectum and had a full bladder (drinking 400-500 mL water 30 minutes before simulation and treatment sessions) before computed tomography (CT) planning and daily treatment. For pelvic and prostate cancer patients, we did not use immobilization device. All patients were scanned in head first supine position. The thermoplastic mask or skin of the patients was marked using radio-opaque labels under laser beams guidance in CT planning step. Slice thickness was $3 \mathrm{~mm}$ in all cases.

CT images were imported into the Varian Eclipse v.13.6 treatment planning software (Varian Medical System Inc, Palo Alto, CA, USA) for 3DCRT treatment planning. The CTV and OARs were contoured by the responsible physician. For brain and H\&N plans, PTV was generated with an isotropic margin of $7 \mathrm{~mm}$. For pelvic cancer cases, CTV-PTV margin of $10 \mathrm{~mm}$ all around were added to the defined CTV. In prostate patients, PTV were defined as CTV plus an isotropic margin of $7 \mathrm{~mm}$. Prescription dose was delivered with 3DCRT on the linear accelerator (Varian Clinac iX) with $6 \mathrm{MV}$ and $18 \mathrm{MV}$ photon beams.

\section{Image Guided Radiotherapy}

Prior to treatment, patients were positioned with a suitable immobilization device. Then, they were setup to treatment room laser and skin marks (or mask marks). Orthogonal portal images were acquired using a flat panel amorphous silicon digital portal imaging device with resolution $1024 \times 768$ pixel. Portal images were acquired at a dose rate 400 monitor unit (MU) per minute and $1 \mathrm{MU}$ were delivered per field for portal acquisition. EPID images were compared to the DRRs (as a reference image) created for the orthogonal portals at $0^{\circ}$ (anterior) and $90^{\circ}$ (lateral) using treatment planning software (TPS). Reference bony landmarks for the comparison of the EPIs and DRRs were listed in Table 1.

Table 1: Reference landmarks in electronic portal images.

\begin{tabular}{|c|c|c|}
\hline Treatment site & $\begin{array}{c}\text { Reference bony } \\
\text { landmarks } \\
\text { in lateral image }\end{array}$ & $\begin{array}{c}\text { Reference bony } \\
\text { landmarks } \\
\text { in AP image }\end{array}$ \\
\hline Head and neck & $\begin{array}{c}\text { External mandible } \\
\text { profile, nasal septum, } \\
\text { maxillary sinus and } \\
\text { the spinous process } \\
\text { of one of lower } \\
\text { cervical vertebrae. }\end{array}$ & $\begin{array}{c}\text { Internal and external } \\
\text { mandible profiles, } \\
\text { skull base and } \\
\text { cervical vertebral } \\
\text { bodies (C2-C4). }\end{array}$ \\
\hline Brain & $\begin{array}{c}\text { Base of the skull, } \\
\text { body and spina of C2 } \\
\text { vertebra. }\end{array}$ & $\begin{array}{c}\text { Nasal septum, } \\
\text { maxillar sinus, } \\
\text { base of posterior } \\
\text { skull, vertebras. }\end{array}$ \\
\hline Pelvic and prostate & $\begin{array}{c}\text { Pubic symphysis, } \\
\text { obturator foramen, } \\
\text { iliac crest, gold } \\
\text { fiducial markers (in } \\
\text { case with prostate } \\
\text { cancer). }\end{array}$ & $\begin{array}{c}\text { Coccyx bone, L5-S1, } \\
\text { pubic symphysis, } \\
\text { gold fiducial markers } \\
\text { (in case with prostate } \\
\text { cancer). }\end{array}$ \\
\hline
\end{tabular}

For H\&N, brain and pelvic cases, EPIs were performed for the first 3 consecutive treatment fractions. Online setup error correction was done for these three fractions. At the fourth fraction, patients were transferred to the new isocenter, with average displacements in the first three fractions and were followed once weekly thereafter. Then, the online setup error correction would apply if correction was needed. For patients with prostate cancer, EPIs were carried out several times per week because we wanted to evaluate the efficacy of fiducial gold marker-based position verification during prostate EBRT for the first time at our institution. Therefore, online setup error correction was carried out for prostate patients. Matching DRRs and portal images were performed using the anatomy matching software (ARIA-record \& verify system).For study the setup errors, the displacement in two translational directions were assessed in each field. The orthogonal portal images were matched using the visible bony landmarks with their respective DRRs. The action level was the displacement greater than 2 $\mathrm{mm}$ in $\mathrm{H} \& \mathrm{~N}$ and brain cases and $3 \mathrm{~mm}$ in pelvic and prostate cases along one direction in which corrected using the linac couch shifts or by correcting the patient position to match the 


\section{Cancer Therapy \& Oncology International Journal}

treatment isocenter. Then, new portal images were acquired. Patient setup errors were assessed along three translational directions (vertical (Y), longitudinal (Z) and lateral (X)).

\section{Statistics}

The systematic and random errors were calculated using the displacement in three translational directions. For H\&N, brain and pelvic cases, the systematic errors were defined as deviations between the planned patient position and average patient position of first three consecutive treatment fractions. The random errors were defined as deviations between different treatment fractions taken weekly during a course of the treatment. Standard deviation (SD) of the systematic errors $(\Sigma)$ and SD of the random errors $(\sigma)$ were analyzed. For prostate cancer patients, $\Sigma$ refers to SD of all individual means, and $\sigma$ is determined through the root mean square of the individual SD of all patients [3]. In addition, we quantified the frequency of 3D vector lengths and calculated the magnitude of $3 \mathrm{D}$ vector using
$\left(\sqrt{\mathrm{VRT}^{2}+\mathrm{LONG}^{2}+\mathrm{LAT}^{2}}\right)$ formula (VRT, LONG and LAT are vertical, longitudinal and lateral setup correction.

\section{Calculation of CTV- PTV margin}

CTV-PTV margins for confidence level p (percentage of patient population) to achieve dose level $d$ (percentage of prescription dose) were calculated using van Herk's formula [9]:

$$
\operatorname{PTV}_{(\mathrm{p}, \mathrm{d})}=\alpha(\mathrm{p}) \cdot \Sigma+\beta(\mathrm{d}) \cdot \sigma
$$

Where $\alpha$ and $\beta$ are a function of $p$ and $d$, respectively. For example, PTV ${ }_{(90,95)}$ assumes that target minimum dose is $95 \%$ to $90 \%$ confidence level.

\section{Results}

In the current study, we analyzed a total of 76, 107, 206 and 359 fractions for $\mathrm{H} \& \mathrm{~N}$, brain, pelvic and prostate, respectively. The SD of systematic and random errors for different treatment sites are summarized in Table 2.

Table 2: The systematic $(\Sigma)$ and random $(\sigma)$ setup errors.

\begin{tabular}{|c|c|c|c|c|c|c|c|c|c|c|c|c|}
\hline Treatment site & \multicolumn{3}{|c|}{ Head and Neck } & \multicolumn{3}{c|}{ Brain } & \multicolumn{3}{c|}{ Pelvic } & \multicolumn{3}{c|}{ Prostate } \\
\hline Direction & VRT & LONG & LAT & VRT & LONG & LAT & VRT & LONG & LAT & VRT & LONG & LAT \\
\hline Systematic error $(\mathrm{mm})$ & 0.70 & 0.86 & 0.60 & 0.61 & 0.80 & 0.93 & 1.3 & 1.26 & 1.51 & 0.69 & 0.86 & 1.00 \\
\hline Random error $(\mathrm{mm})$ & 0.50 & 0.45 & 0.90 & 0.30 & 0.40 & 0.72 & 0.63 & 0.92 & 0.94 & 2.11 & 2.30 & 2.31 \\
\hline
\end{tabular}

Figure 1a.

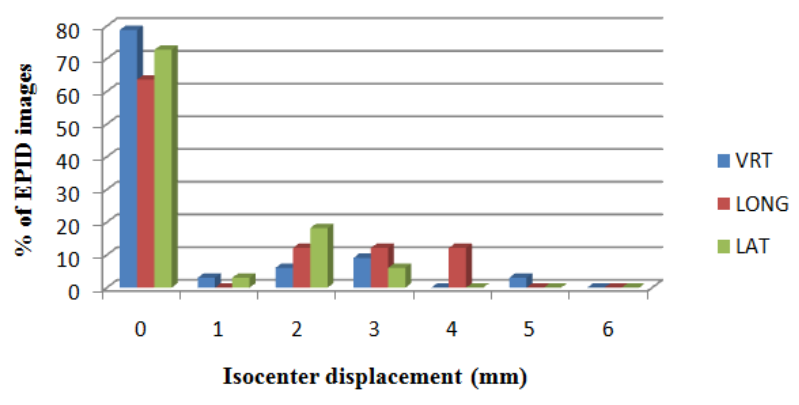

Figure 1b.

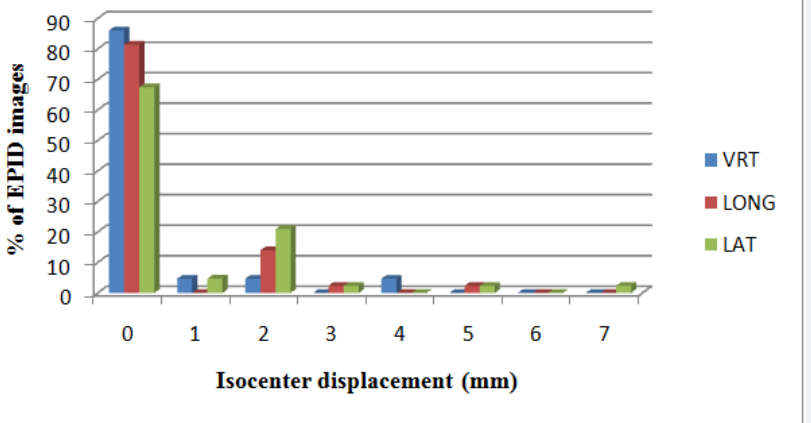

Figure 1: The frequency of the systematic (a) and random (b) displacements for the patients with head and neck cancer.

Figure 2a.

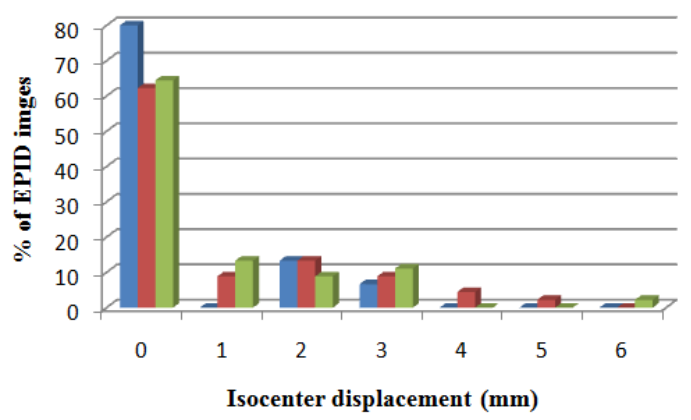

Figure 2b.

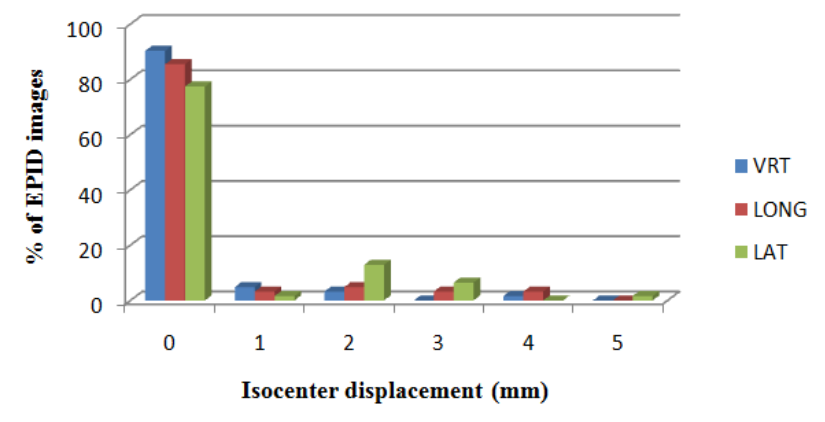

Figure 2: The frequency of the systematic (a) and random (b) displacements for the patients with brain cancer. 


\section{Cancer Therapy \& Oncology International Journal}
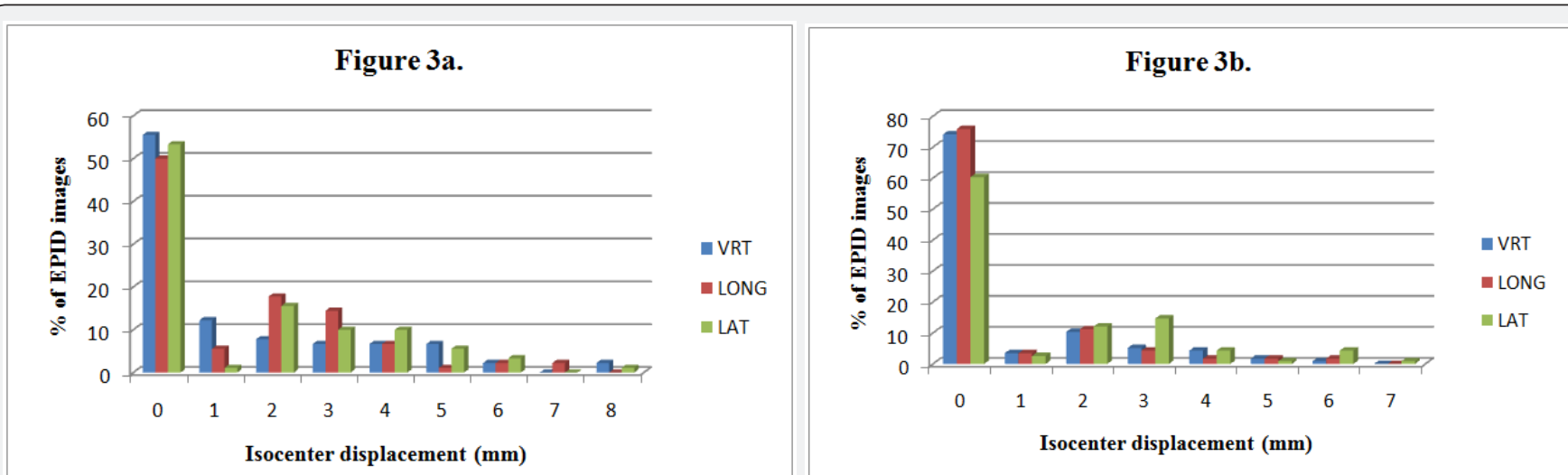

Figure 3: The frequency of the systematic (a) and random (b) displacements for the patients with pelviccancer.

The largest magnitude of systematic errors was found in pelvic cases on the three axial directions relative to other cases. The smallest systematic errors were observed for $\mathrm{H} \& \mathrm{~N}$ in lateral direction. In addition, the random errors in prostate were large on the three dimensions in contrast to the other treatment sites. The random errors in brain had smallest value than that in the other treatment sites.The frequency of systematic and random errors for H\&N, brain and pelvic cancers in vertical, longitudinal and lateral directions are shown in Figures 1-3. Overall, most of the systematic and random displacements were $\leq 3 \mathrm{~mm}$ for $\mathrm{H} \& \mathrm{~N}$, brain and pelvic cancers in the vertical, longitudinal and lateral directions.

The average $( \pm$ SD) prostate translational shifts per patients in the three directions are given in Figure 4. The average prostate shifts were $0.23 \mathrm{~mm}, 0.14 \mathrm{~mm}$ and $-0.42 \mathrm{~mm}$ in the vertical, longitudinal and lateral directions, respectively, as shown in Figure 4a-4c.Table 3 summarizes the CTV-PTV margins calculated for achieving adequate coverage with a confidence level between 90\%-99\% in each translational direction. Table 4 shows the cumulative percentages of $3 \mathrm{D}$ vector lengths in the setup corrections for the all cases. Three-dimensional vector displacements $\geq 7 \mathrm{~mm}$ was $0 \%$ for brain cases and rare for other treatment sites. The frequencies of 3D vector lengths are related to the treatment site. The percentage of $3 \mathrm{D}$ vector lengths in prostate and pelvic cases is similar. The frequencies of 3D vector lengths of translational displacements also are similar between H\&N and brain cases. For H\&N and brain cases, the distribution of 3D vector length reduces rapidly from a starting length $\geq 1 \mathrm{~mm}$ in contrast to pelvic and prostate cases.
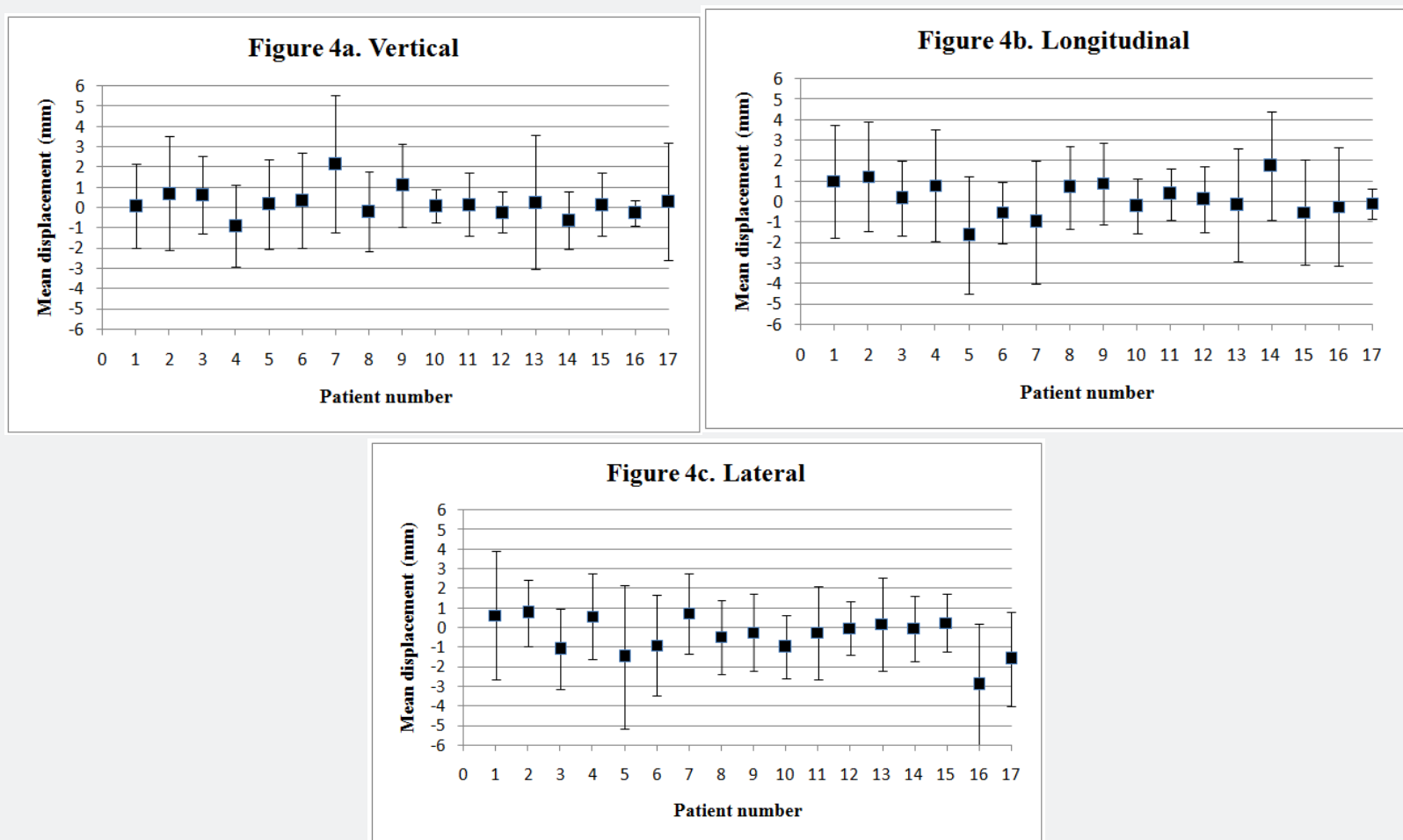

Figure 4: The mean and standard deviation of prostate shifts in the vertical (a), longitudinal (b) and lateral (c) directions for 17 patients. 


\section{Cancer Therapy \& Oncology International Journal}

Table 3: PTV margin (mm) for various treatment sites.

\begin{tabular}{|c|c|c|c|c|c|c|c|c|c|c|}
\hline \multicolumn{11}{|c|}{ Confidence level (\%) } \\
\hline \multirow[b]{2}{*}{ Patients } & \multirow[b]{2}{*}{ Dose level } & \multicolumn{3}{|c|}{ VRT (mm) } & \multicolumn{3}{|c|}{ LONG (mm) } & \multicolumn{3}{|c|}{ LAT (mm) } \\
\hline & & $90 \%$ & $95 \%$ & $99 \%$ & $90 \%$ & $95 \%$ & $99 \%$ & $90 \%$ & $95 \%$ & $99 \%$ \\
\hline \multirow{2}{*}{$\begin{array}{c}\mathrm{H} \& \mathrm{~N} \\
\text { patients }\end{array}$} & $95 \%$ & 2.10 & 2.30 & 2.70 & 2.47 & 2.71 & 3.20 & 2.13 & 2.30 & 2.65 \\
\hline & $99 \%$ & 2.22 & 2.43 & 2.83 & 2.58 & 2.83 & 3.32 & 2.35 & 2.53 & 2.87 \\
\hline \multirow{2}{*}{$\begin{array}{c}\text { Brain } \\
\text { patients }\end{array}$} & $95 \%$ & 1.74 & 1.91 & 2.26 & 2.28 & 2.51 & 2.97 & 2.83 & 3.10 & 3.63 \\
\hline & $99 \%$ & 1.81 & 1.98 & 2.33 & 2.38 & 2.61 & 3.70 & 3.01 & 3.28 & 3.81 \\
\hline \multirow{2}{*}{$\begin{array}{c}\text { Pelvic } \\
\text { patients }\end{array}$} & $95 \%$ & 3.70 & 4.07 & 4.81 & 3.80 & 4.16 & 4.87 & 4.43 & 4.87 & 5.73 \\
\hline & $99 \%$ & 3.85 & 4.22 & 4.96 & 4.02 & 4.39 & 5.11 & 4.67 & 5.10 & 5.96 \\
\hline \multirow{2}{*}{$\begin{array}{l}\text { Prostate } \\
\text { patients }\end{array}$} & $95 \%$ & 3.20 & 3.40 & 3.80 & 3.76 & 4.01 & 4.50 & 4.12 & 4.41 & 4.98 \\
\hline & $99 \%$ & 3.73 & 3.93 & 4.32 & 4.33 & 4.58 & 5.07 & 4.70 & 4.98 & 5.55 \\
\hline
\end{tabular}

Table 4: The cumulative frequencies (\%) of 3D vector lengths.

\begin{tabular}{|c|c|c|c|c|}
\hline 3D vector length (mm) & Head and Neck & Brain & Pelvic & Prostate \\
\hline$\geq 1$ & 46.053 & 38.32 & 62.62 & 46.02 \\
\hline$\geq 3$ & 22.37 & 21.49 & 47.573 & 28.97 \\
\hline$\geq 4$ & 13.6 & 9.34 & 29.61 & 20.056 \\
\hline$\geq 5$ & 5.26 & 3.74 & 4.95 & 7.24 \\
\hline$\geq 7$ & 1.316 & 0 & 0.485 & 2.51 \\
\hline$\geq 10$ & 0 & 0 & 0 & 0.56 \\
\hline
\end{tabular}

\section{Discussion}

Monitoring of patient positioning can be performed by EPID. Thus, any changes in the treatment isocenter will be corrected. In the present study, we evaluated the inter-fractional set up errors for various treatment sites of 73 patients using EPID. In addition, CTV-PTV margins were calculated with van Herk's formula [9]. In our institution, the action level is $2 \mathrm{~mm}$ in $\mathrm{H} \& \mathrm{~N}$ and brain cases and $3 \mathrm{~mm}$ in pelvic and prostate cases for translational direction. The results from our study showed that more than $70 \%$ of the systematic and random error displacements were less than $2 \mathrm{~mm}$ for H\&N and brain sites and less than $3 \mathrm{~mm}$ for pelvic site in three directions (Figures 1-3). For the prostate cases, about $84 \%, 77 \%$ and $77 \%$ of the setup displacements were less than $3 \mathrm{~mm}$ in the vertical, longitudinal and lateral directions, respectively (the results are not shown). Overall, the systematic and random errors were small in H\&N and brain in contrast to pelvic and prostate regions because these treatment sites are rigid and day-to-day variations in set up geometry are minimal [10]. Previous studies reported that the several factors associated with fixation can lead to setup uncertainties in H\&N and brain cases. These factors are including swelling in tumor region and reduction in body countering owing to weighting loss during radiotherapy that lead to changes in fixation relative to the onset of treatment [11-14]. Overall, these issues were low at our institution. Furthermore, if these factors were observed, we carried out a new CT planning with a change in degree of patient stabilization.

There are multiple factors which can lead to setup uncertainties for the pelvic and prostate cases. Target volume position in pelvic and prostate cancer can change owing to intestinal movement and vary filling in the bladder and rectum [14-16]. Meanwhile, skin marks can easily move in these treatment sites, and can lead to setup error $[17,18]$. Using thin lines on the patient's skin as well as good customized skin fiducial markers and accuracy of laser room can reduce setup deviations in theses treatment sites.

We found that in the all treatment sites, the random errors were greater in the lateral direction compared to two other directions, as shown in Table 2 . This is probably due to the optical illusion and the inaccuracy in matching laser and line on the patient body. In a review article, Hurkmans et al. [19] reported that the systematic and random errors in the routine clinical practice can be less than $2 \mathrm{~mm}$ (1SD) for $\mathrm{H} \& \mathrm{~N}, 3 \mathrm{~mm}$ 


\section{Cancer Therapy \& Oncology International Journal}

(1SD) for pelvic and $2.5 \mathrm{~mm}$ (1SD) for prostate. The findings of our study were in line with Hurkmans et al. study. As shown in Table 5, the magnitude of systematic and random errors for pelvic and prostate cases in our study are similar or less than other studies, while we did not use knee support and foot rest for pelvic and prostate cancer patients [17,20-22]. Compared to $\mathrm{H} \& \mathrm{~N}$ and brain cases in the current study, these are larger. This primarily depends on the nature of treatment site and how the patient is immobilized.

To compare the results with other published study, we have considered PTV $(90,95)$ margin. In our study, the calculated CTVPTV margin for H\&N cases in the vertical, longitudinal and lateral directions were $2.10 \mathrm{~mm}, 2.47 \mathrm{~mm}$ and $2.13 \mathrm{~mm}$, respectively. In another study, Gupta et al. assessed the setup errors in 25 patients with H\&N lesions using a camera-based EPID that immobilized with thermoplastic mask. The systematic errors were $0.96 \mathrm{~mm}, 1.2 \mathrm{~mm}$ and $0.98 \mathrm{~mm}$ in the vertical, longitudinal and lateral directions, respectively. The random errors were 1.94 $\mathrm{mm}, 2.48 \mathrm{~mm}$ and $1.97 \mathrm{~mm}$ in the vertical, longitudinal and lateral directions, respectively. They obtained a PTV margin $3.76 \mathrm{~mm}$, $4.74 \mathrm{~mm}$ and $3.83 \mathrm{~mm}$ for the vertical, longitudinal and lateral directions [23]. The results of this study are different to the findings of current work. In the current work, we have changed the isocenter in the fourth fraction, which resulted in reduction of the systematic errors. Another difference can be attributed to the frequency of online verification. Rudat et al. [24] reported that setup margin reduces with increasing frequency of online verification. Gupta et al. [23] investigated displacements in 93 fractions for 25 patients whereas we evaluated 76 fractions for 11 patients. Furthermore, patients with $H \& N$ and brain tumors in our institution had to have a uniform size of hair throughout the treatment period. This causes the thermoplastic mask to be easily fixed.

In 2016, Kanakavelu et al. [22] evaluated the setup accuracy and determined optimal PTV margin for H\&N, brain and prostate using MV CBCT and MV planar imaging. The CTV-PTV margin was calculated using van Herk's formula $(1.75 \mathrm{~mm}, 2.98 \mathrm{~mm}$ and $3.45 \mathrm{~mm}$ for $\mathrm{H} \& \mathrm{~N}, 1.86 \mathrm{~mm}, 3.36 \mathrm{~mm}$ and $3.42 \mathrm{~mm}$ for brain and $4.52 \mathrm{~mm}, 4.56 \mathrm{~mm}$ and $5.02 \mathrm{~mm}$ for prostate in the vertical, longitudinal and lateral directions, respectively) [22]. Data of this study showed PTV margins for $\mathrm{H} \& \mathrm{~N}$ and prostate are comparable to those in the present study. In our institution, prostate cancer patients had to have a full bladder and empty rectum during CT planning and daily treatment sessions that lead to a reduction in the inter-fractional variations in the prostate gland. From our results, it can be seen that PTV margin in the prostate cases for different confidence levels in the vertical direction was less than $5 \mathrm{~mm}$. The reduction in PTV margin in this direction can be resulted in decrease of the rectal toxicity. Studies have been shown that reduction in PTV margin for prostate cancer is possible using the implanted fiducial markers. The CTV-PTV margin of $5 \mathrm{~mm}$ was suggested with fiducial markers [25]. The results of our study are in line with this suggestion.

Although the systematic errors for brain site in our study are comparable to Paul et al. study (Table 5), our calculated margin is tighter. Paul et al. determined the PTV margin for 32 brain cancer patients with EPID, and reported a margin $3.7 \mathrm{~mm}, 3.1$ $\mathrm{mm}$ and $4 \mathrm{~mm}$ in the vertical, longitudinal and lateral directions, respectively [26]. The difference in the calculated PTV margin in the two studies is mainly due to the random setup errors that can be attributed to patient-related factors and the tightness of the thermoplastic mask drown on the head.

Table 5: Systematic and random setup errors/ comparison with published data.

\begin{tabular}{|c|c|c|c|c|c|c|c|}
\hline \multirow{2}{*}{\multicolumn{2}{|c|}{$\begin{array}{c}\text { Treatment site } \\
\text { Direction }\end{array}$}} & \multicolumn{3}{|c|}{ Systematic error ( $\mathrm{mm}$ ) } & \multicolumn{3}{|c|}{ Random error (mm) } \\
\hline & & \multirow{2}{*}{$\begin{array}{l}\text { VRT } \\
0.96\end{array}$} & \multirow{2}{*}{$\begin{array}{c}\text { LONG } \\
1.20 \\
\end{array}$} & \multirow{2}{*}{$\begin{array}{l}\text { LAT } \\
0.98\end{array}$} & \multirow{2}{*}{$\begin{array}{l}\text { VRT } \\
1.94 \\
\end{array}$} & \multirow{2}{*}{$\begin{array}{c}\text { LONG } \\
2.48 \\
\end{array}$} & \multirow{2}{*}{$\begin{array}{l}\text { LAT } \\
1.97\end{array}$} \\
\hline \multirow{4}{*}{$\begin{array}{l}\text { Head } \\
\text { and } \\
\text { neck }\end{array}$} & Gupta et al. [23] & & & & & & \\
\hline & $\begin{array}{c}\text { Kanakavelu et } \\
\text { al. [22] }\end{array}$ & 0.50 & 0.93 & 1.14 & 0.73 & 0.92 & 0.86 \\
\hline & Present study & 0.70 & 0.86 & 0.60 & 0.50 & 0.45 & 0.90 \\
\hline & Paul et al. [26] & 1.00 & 0.90 & 1.10 & 1.30 & 1.20 & 1.50 \\
\hline \multirow{3}{*}{ Brain } & $\begin{array}{l}\text { Kanakavelu et } \\
\text { al. [22] }\end{array}$ & 0.54 & 1.09 & 1.13 & 0.74 & 0.93 & 0.85 \\
\hline & Present study & 0.61 & 0.80 & 0.93 & 0.30 & 0.40 & 0.72 \\
\hline & $\begin{array}{l}\text { Gildersleve et } \\
\text { al. [21] }\end{array}$ & 2.50 & 2.60 & 1.60 & 2.60 & 2.00 & 1.50 \\
\hline \multirow{3}{*}{ Pelvic } & $\begin{array}{l}\text { Thasanthan et } \\
\text { al. [20] }\end{array}$ & 2.70 & 3.30 & 2.57 & 2.34 & 1.60 & 2.57 \\
\hline & Present study & 1.30 & 1.26 & 1.51 & 0.63 & 0.92 & 0.94 \\
\hline & $\begin{array}{l}\text { van der Heide } \\
\text { et al. [17] }\end{array}$ & 4.80 & 2.90 & 2.20 & 3.50 & 2.30 & 2.00 \\
\hline \multirow[t]{2}{*}{ Pelvic } & $\begin{array}{c}\text { Kanakavelu et } \\
\text { al. [22] }\end{array}$ & 1.47 & 1.48 & 1.61 & 1.19 & 1.21 & 1.41 \\
\hline & Present study & 0.69 & 0.86 & 1.00 & 0.94 & 2.11 & 2.31 \\
\hline
\end{tabular}




\section{Cancer Therapy \& Oncology International Journal}

Thasanthan et al. [20] in their work reported that in 50 patients with pelvic lesions, PTV margin in the vertical, longitudinal and lateral directions are $8.38 \mathrm{~mm}, 9.33 \mathrm{~mm}$ and $7.56 \mathrm{~mm}$, respectively. As shown in Table 3, our findings are different with their results. The first two fractions of the course of treatment were assessed by them [20]. According to our experience, the magnitude of patient setup errors at initial treatment sessions is large owing to the lack of patient comfort in the therapeutic position and immobilization device. Thus, we think this can be a reason for this difference, as well as the lower number of investigated fraction for determining the shifts in study by Thasanthan et al. [20].

The cumulative frequencies of $3 \mathrm{D}$ vector lengths of $\geq 4 \mathrm{~mm}$ were $13.6 \%, 9.34 \%, 29.61 \%$ and $28.97 \%$ in H\&N, brain, pelvic and prostate cases, respectively. The systematic and random errors for $\mathrm{H} \& \mathrm{~N}$ and brain sites were $\leq 0.93 \mathrm{~mm}$. These results can be related to using the mask for $\mathrm{H} \& \mathrm{~N}$ and brain patients [27]. From the results, the 3D vector lengths of displacements depend on the tumor site and were in good agreement with the results of pervious study that showed the 3D vector length of translational shift, in contrast with the 3D vector length of rotational shift, are associated with the treatment area [14].CTV-PTV margins for various confidence levels were listed in Table 3. Our setup with EPID indicated target minimum dose of $99 \%$ when using a target volume to PTV margin less than $4 \mathrm{~mm}$ for H\&N and brain sites and less than $6 \mathrm{~mm}$ for pelvic and prostate cases to achieve a $95 \%$ confidence level. For tumors that are in regions with high uncertainty such as prostate, it is more reasonable to consider upper limit of the calculated margin.

Although, we can reduce setup errors using correction protocol, those will not eliminate. However, there are the intrafractional variations and uncertainty in organ delineation [27-29]. Overall, the results of determination of patient setup uncertainties related to various factors such as immobilization device, patient collaboration in the implementation of setup procedure, the geometrical accuracy of the treatment machine, accuracy of the lasers in the treatment machine and room, the image verification system and the time taken to setup of the patient can also affect the accuracy of the setup. Generally, we spent an adequate time for the setup of the patient in the treatment position.

There are two main limitations in this study. First, the intrafractional setup errors were not considered. Intra-fractional organ motion and intra-fractional variations in each patient are important for accurate determination of setup uncertainties. Second, the rotational setup errors were not evaluated in this study. Therefore, these data should be analyzed for future studies.

\section{Conclusion}

In this study, for first time in our institution, the setup errors and CTV-PTV margins were determined for various treatment sites. The setup errors depend on tumor site. The use of image guidance technique is an effective tool for setup verification. From our study, the optimal CTV-PTV margin can be acquired. The reduction in CTV-PTV margins is an effective way to reduce radiation-related complications in normal tissues.

\section{Acknowledgement}

We are tankful to staff of the Roshana Radiation Oncology Center, Tehran.

\section{References}

1. Jones D (1994) ICRU Report 50-Prescribing, Recording and Reporting Photon Beam Therapy. Medical Physics 21(6): 833-834.

2. Landberg T, Chavaudra J, Dobbs J, Gerard JP, Hanks G, et al. (1999) Report 62. Journal of the International Commission on Radiation Units and Measurements os32(1): NP-NP.

3. van Herk M (2004) Errors and margins in radiotherapy. Seminars in radiation oncology 14(1): 52-64.

4. Oh SA, Yea JW, Kang MK, Park JW, Kim SK (2016) Analysis of the Setup Uncertainty and Margin of the Daily ExacTrac 6D Image Guide System for Patients with Brain Tumors. PLoS One 11(3): e0151709.

5. Macarena Cubillos Mesías, Judit Boda-Heggemann, Johannes Thoelking, Frank Lohr, Frederik Wenz, et al. (2016) Quantification and Assessment of Interfraction Setup Errors Based on Cone Beam CT and Determination of Safety Margins for Radiotherapy. Plos One 11(3): e0150326.

6. Mahdavi SR, Jazayeri Gharehbagh E, Mofid B, Jafari AH, Nikoofar AR (2017) Accuracy of the dose delivery in prostate cancer patients-using an electronic portal imaging device (EPID). Int J Radiat Res 15(1): 3947.

7. Langmack KA (2001) Portal imaging. The British journal of radiology 74(885): 789-804.

8. Herman MG (2005) Clinical use of electronic portal imaging. Semin Radiat Oncol 15(3): 157-167.

9. Van Herk M, Remeijer P, Rasch C, Lebesque JV (2000) The probability of correct target dosage: dose-population histograms for deriving treatment margins in radiotherapy. Int J Radiat Oncol Biol Phys 47(4): 1121-1135.

10. Murthy KK, Al-Rahbi Z, Sivakumar SS, Davis CA, Ravichandran R, et al. (2008) Verification of setup errors in external beam radiation therapy using electronic portal imaging. J Med Phys 33(2): 49-53.

11. Schubert LK, Westerly DC, Tome WA, Mehta MP, Soisson ET, et al. (2009) A comprehensive assessment by tumor site of patient setup using daily MVCT imaging from more than 3,800 helical tomotherapy treatments. Int J Radiat Oncol Biol Phys 73(4): 1260-1209.

12. Den RB, Doemer A, Kubicek G, Bednarz G, Galvin JM, et al. (2010) Daily image guidance with cone-beam computed tomography for head-andneck cancer intensity-modulated radiotherapy: a prospective study. Int J Radiat Oncol Biol Phys 76(5): 1353-1359.

13. Li H, Zhu XR, Zhang L, Dong L, Tung S, et al. (2008) Comparison of 2D radiographic images and $3 \mathrm{D}$ cone beam computed tomography for positioning head-and-neck radiotherapy patients. Int J Radiat Oncol Biol Phys 71(3): 916-925.

14. Oh YK, Baek JG, Kim OB, Kim JH (2014) Assessment of setup uncertainties for various tumor sites when using daily CBCT for more than 2200 VMAT treatments. Journal of applied clinical medical physics. 15(2): 4418. 


\section{Cancer Therapy \& Oncology International Journal}

15. Padhani AR, Khoo VS, Suckling J, Husband JE, Leach MO, et al. (1999) Evaluating the effect of rectal distension and rectal movement on prostate gland position using cine MRI. Int J Radiat Oncol Biol Phys 44(3): 525-533.

16. Dawson LA, Litzenberg DW, Brock KK, Sanda M, Sullivan M, et al. (2000) A comparison of ventilatory prostate movement in four treatment positions. Int J Radiat Oncol Biol Phys 48(2): 319-323.

17. Van der Heide UA, Kotte ANTJ, Dehnad H, Hofman P, Lagenijk JJW, et al. (2007) Analysis of fiducial marker-based position verification in the external beam radiotherapy of patients with prostate cancer Radiother Onco 82(1): 38-45.

18. Bel A, Vos PH, Rodrigus PT, Creutzberg CL, Visser AG, et al. (1996) High-precision prostate cancer irradiation by clinical application of an offline patient setup verification procedure, using portal imaging. Int J Radiat Oncol Biol Phys 35(2): 321-332.

19. Hurkmans CW, Remeijer P, Lebesque JV, Mijnheer BJ (2001) Set-up verification using portal imaging; review of current clinical practice. Radiother Oncol 58(2): 105-120.

20. Thasanthan L, Piyasena W, Croos A, Dhanushia R, Narayanan PP (2014) Assessment of Three-Dimensional Set-up Errors in Pelvic Radiation Therapy. J Cancer Prev Curr Res 1(2).

21. Gildersleve J, Dearnaley DP, Evans PM, Swindell W (1995) Reproducibility of patient positioning during routine radiotherapy, as assessed by an integrated megavoltage imaging system. Radiotherapy and oncology : journal of the European Society for Therapeutic Radiology and Oncology 35(2): 151-160.

22. Kanakavelu N, Jebaseelan SJ (2016) Determination of patient setup error and optimal treatment margin for intensity modulated radiotherapy using image guidance system. J BUON 21(2): 505-511.

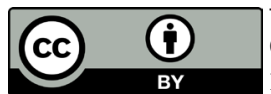

This work is licensed under Creative Commons Attribution 4.0 License

DOI: $10.19080 / C T O I J .2018 .11 .555808$
23. Gupta T, Chopra S, Kadam A, Agarwal JP, Devi PR, et al. (2007) Assessment of three-dimensional set-up errors in conventional head and neck radiotherapy using electronic portal imaging device. Radiat Oncol 2: 44

24. Rudat V, Hammoud M, Pillay Y, Alaradi AA, Mohamed A, et al. (2011) Impact of the frequency of online verifications on the patient set-up accuracy and set-up margins. Radiat Oncol 6: 101.

25. Yartsev S, Bauman G (2016) Target margins in radiotherapy of prostate cancer. Br J Radiol 89(1067): 20160312.

26. Paul S, Roy S, Agrawal S, Munshi A, Jassal K, Ganesh T, et al. Prospective comparative evaluation of planning target volume margin for brain intensity modulated radiotherapy utilizing hybrid online imaging modalities. Clinical Cancer Investigation Journal 4(5): 645-650.

27. Gilbeau L, Octave-Prignot M, Loncol T, Renard L, Scalliet P, et al. (2001) Comparison of setup accuracy of three different thermoplastic masks for the treatment of brain and head and neck tumors. Radiother Oncol 58(2): 155-162.

28. Stroom IC, de Boer HC, Huizenga H, Visser AG (1999) Inclusion of geometrical uncertainties in radiotherapy treatment planning by means of coverage probability. Int J Radiat Oncol Biol Phys 43(4): 905919

29. Beltran C, Krasin MJ, Merchant TE (2011) Inter- and intrafractional positional uncertainties in pediatric radiotherapy patients with brain and head and neck tumors. Int J Radiat Oncol Biol Phys 79(4): 12661274

Your next submission with Juniper Publishers will reach you the below assets

- Quality Editorial service

- Swift Peer Review

- Reprints availability

- E-prints Service

- Manuscript Podcast for convenient understanding

- Global attainment for your research

- Manuscript accessibility in different formats

( Pdf, E-pub, Full Text, Audio)

- Unceasing customer service

Track the below URL for one-step submission

https://juniperpublishers.com/online-submission.php 